\title{
BUNG KARNO, FENOMENA KEBAHASAAN DAN LAHIRNYA INDONESIA MERDEKA
}

\author{
Edy Subali*
}

\begin{abstract}
Abstrak
"Dibawah Bendera Revolusi merupakan kumpulan tulisan Bung Karno dalam majalah luar dan dalam negeri, yang terbit antara tahun 1926 sampai dengan tahun 1940-an. Bahasanya terikat konteks; penggunaan kata dan gaya bahasa sebagai wujud aksi dan reaksi terhadap konteks kondisi sosial, ekonomi dan politik yang memprihatinkan sebagai akibat sistem ekonomi kapitalis yang dijalankan penguasa asing-Belanda di Indonesia ketika itu.

Kata-kata dan gaya bahasanya berenergi maskulin, "kelaki-lakian", berkonotasi sebagai aksi bukan narasi, aktivis kehidupan bukan pengamat dan penjelas kehidupan, menggugah dan membangunkan kesadaran bukan meninabobokkan, berfungsi seperti "kejut listrik" bahkan "teror" terhadap kesadaran. Strateginya, konotasi dirangsang, polisemi diperluas optimal dan sinonimi serta antonimi diaktifkan.
\end{abstract}

Kata kunci: konteks, metafor, wacana, gaya bahasa.

Judul kumpulan teks buah pikiran Bung Karno diberi nama Dibawah Bendera Revolusi (DBR). Di dalamnya terdapat 60 teks dengan judul dan topik beragam, dari masalah Nasakom, Kapitalisme-Imperialisme hingga teks tulisannya yang berjudul Kuasanya Kerongkongan.

Kajian terhadap bahasa Bung Karno berarti analisis terhadap bahasa yang dimanfaatkan Bung Karno sebagai media komunikasi politik, sosial dan ekonomi pada masa pemerintahan asing Belanda di Indonesia, yaitu antara tahun 1926 sampai dengan tahun 1941. Oleh karena itu, bahasanya terikat konteks situasi dan kondisi sosial, politik dan ekonomi pada masa tersebut. Bung Karno aktif berkomunikasi kepada publik pada masa tersebut bukan semata-mata karena gemar berbahasa (berpidato atau mengarang), tetapi juga karena faktor konteks situasi dan kondisi sosial-ekonomi masyarakat kita yang berada dalam keadaan terjajah dan ingin lepas merdeka dari penjajahan Belanda. Pernyataan berikut ini dapat menjadi indikator bahwa bahasa Bung Karno terikat konteks.

\footnotetext{
* Dosen pada Jurusan MKU FMIPA ITS.

jsh Jurnal Sosial Humaniora, Vo. 2, No. 1, Juni 2009
} 
Bung Karno gemar mengarang dan kemudian datanglah zaman yang dalam sejarah kehidupan Bung Karno dapat dianggap masa pencurahan pikiran dalam karang-mengarang, yaitu semasa Bung Karno bersama-sama dengan kawan sefaham beliau mendirikan dan menggerakkan Partai Nasional Indonesia (PNI) dan Partai Indonesia (Partindo) serta semasa beliau diasingkan ke Endeh dan akhirnya ke Bengkulen. Pada zaman penjajahan untuk menyimpan buah pikiran para pemimpin pergerakan terutama buah pena Bung Karno, baik yang berupa karangan maupun yang berupa pidato-pidato diperlukan keberanian bagi para penyimpannya (DBR:1964).

Pernyataan tersebut mengisyaratkan bahwa bahasa Bung Karno merupakan aksi dan reaksi terhadap konteks. Kapan, di mana dan dalam suasana yang bagaimana bahasa Bung Karno yang berupa wacana atau teks digelar dan menjadi wacana publik? Praktik wacana yang bernuansa retorika sebagaimana terhimpun dalam DBR digelar antara tahun 1926 sampai tahun 1941. Praktik wacana tersebut menjadi wacana publik melalui media Suluh Indonesia Muda, Fikiran Ra'jat, Pandji Islam, Pemandangan dan Pembangun.

Berdasar pada angka tahun tersebut berarti bahasa sebagai praktik wacana digelar kepada publik pada masa Indonesia dikuasai dan diperintah oleh pemerintahan asing-Belanda. Tahun 1830 pemerintahan tersebut menerapkan Tanam Paksa dan mulai tahun 1870 ditanamkan faham liberal (Kartodihardjo, Poesponegoro dan Notosusanto, 1977:74 dan 97). Faham liberal dan sistem ekonomi kapitalis yang dibawa dan diterapkan pemerintah asing-Belanda mengakibatkan modal swasta asing dengan leluasa menanamkan modalnya dalam berbagai kegiatan di Jawa maupun di luar Jawa. "Modal asing harus terus mengerumuni Indonesia, seperti semut mengerumuni wadah gula", kata Bung Karno (Indonesia Menggugat, Pratiwi (ed), 2001:65). Perkebunan kopi, teh, tembakau, kapas dan lain-lain yang termasuk tanaman dan dagangan eksport merupakan contohnya. Akibatnya, terjadi penyewaan tanah, masuknya sistem uang dengan konsekuensi lahirnya buruh-buruh tani dan pabrik serta menipisnya tradisi gotong-royong. Sebaliknya, import barang-barang jadi yang diproduksi oleh industri-industri asing semakin memperburuk bagi usaha-usaha kerajinan rakyat pribumi.

Jika Yohannes van den Bosch, gubernur jenderal yang diangkat pemerintah Belanda untuk Indonesia (1830) dengan sistem Tanam Paksa menjadikan 
Indonesia perusahaan negara maka para liberalis menganggap Indonesia sebagai perusahaan swasta. Keduanya sama-sama menghendaki Indonesia sebagai "perusahaan" yang menghasilkan laba surplus untuk ditransfer ke negeri Belanda, (Kartodihardjo, Poesponegoro dan Notosusanto, 1977:102).

Berdasar kenyataan tersebut kondisi ekonomi, sosial dan budaya masyarakat Indonesia semakin lemah karena sistem politik pemerintah kolonial yang diskriminatif dan eksploitatif. Semuanya itu dipahami dan menjadi keprihatinan Bung Karno. Suasana memprihatinkan inilah yang cenderung meresapi kognisi dan afeksi Bung Karno dan dapat menjadi alasan signifikan untuk terbawa ke dalam bahasanya. Dengan demikjan, bahasanya cenderung merupakan aksi dan reaksi terhadap suasana tersebut dengan harapan membangun character-building dan nation-building. Bur Rasuanto (Waluyo dan Kleden (Ed.), 1981:204) menjelaskan: “Sejarah kebangsaan menuju negara Indonesia merdeka karena digerakkan oleh sajak-sajak, novel-novel, ciptaan-ciptaan W.R. Supratman, tulisan Bung Karno, Yamin dan lain-lainnya.” Alfian pun (1986:8889) berpendapat serupa:

Dengan meneliti tulisan-tulisannya, Soekarno-Hatta sebagai penjelmaan kesadaran bangsanya, mampu melahirkan pemikiran-pemikiran cemerlang dalam tahun-tahun dua puluhan, tiga puluhan dan pertengahan pertama empat puluhan. Ada tiga sifat sehingga generasi Soekarno-Hatta dapat menggerakkan sejarah kebangsaan, (1) mereka berani memahami diri bangsanya secara kritis dan jujur, (2) terbuka terhadap perubahan dan pembaharuan, (3) rasa solidaritas yang dalam terhadap sesama bangsanya. Perjalinan tiga sifat dalam diri mereka berakibat berkembangnya dinamika intelektual; ide-ide baru yang segar dan cemerlang bermunculan dan tersosialisasikan dalam wacana-wacana dan ruangruang publik. Dialog dan polemik selain dapat mempertajam pisau analisisnya juga dapat menawarkan dan memberikan alternatif pemikiran-pemikiran baru bagi masyarakat majemuk terjajah.

Bahasanya dapat dianalogikan dengan narasi Seribu Satu Malam. Bung Karno dengan memanfaatkan bahasa yang pada dirinya tidak terbatas berusaha menggali, memanipulasi dan memfungsikan potensi kekuatan bahasa dengan harapan dapat menemukan ruang-ruang untuk mengartikulasikan serta mengaktualisasikan fantasi, imajinasi dan mimpi-mimpi yang mampu membebaskan masyarakat majemuk terjajah dari penderitaan, bahkan kematiannya. 
Dengan cara pandang tersebut Bung Karno cenderung ingin lepas-bebas melakukan aksi diri dengan atau dalam bahasa. Halliday (Sutjaja, dalam PELLBA 3, 1990:68-69) menyebutnya fungsi ideal, yaitu menggambarkan pengalaman lahir-batin atas realitas yang terjadi dalam masyarakat. Menggunakan terminologi Michel Foucault (Suyono, 2002:138-141), Bung Karno melakukan sesuatu untuk masa depan bangsanya dengan bahasa transgresi, yaitu:

Bahasa yang bebas dari keterikatan dan tindasan diskursivitas; bahasa yang memiliki daya-daya yang mampu mengekspresikan kemungkinan situasi-situasi manusia; bahasa teror bagi bangunan-bangunan pengetahuan yang menjadi parameter bagi mitos humanis; bahasa perang melawan adanya rezim keteraturan pengetahuan tertentu yang telah tertanam lama. Penulisan diposisikan sebagai berperang sehingga ia berfungsi sebagai bedil, taktik atau sentolop. Saya (Foucault, pen.) ingin buku-bukunya menjadi semacam pisau bedah, bom molotov, atau medan ranjau yang membuat seseorang gosong bila membaca pada posisi-posisi peledakan .... Saya boleh jadi adalah seorang pedagang senjata, seorang taknisi, seorang penunjuk sasaran-sasaran, seorang pembuat peta, seorang kartografer, seorang serdadu berdarah baja.

Berikut ini contoh bentuk, rupa dan perangai bahasa retorika Bung Karno. Judul teks "Saya Kurang Dinamis." Isinya tanggapan Bung Karno terhadap tuduhan majalah "Adil" bahwa dirinya dianggap terlalu dinamis tentang masalah tabir atau sekat antara laki-laki dan perempuan.

Saja suka sekali membongkar. Hanja dengan tjara membongkar orang bisa mengewek-ewek publik supaja ia bangun dan memperhatikan suatu soal. Publik selalu mengantuk dan bertabiat membeku. ... Kalau orang mau membangunkan perhatian publik, orang mesti ambil palu godam jang besar, dan pukulkan palu itu diatas medja sehingga seperti guntur. ... Saja memang suka sekali "main palu godam," agar supaja suara pukulannja itu menterperandjatkan chalajak yang mau "angler-angleran" sahadja sehingga orang lantas mulai ramai berdebat dan berpikir (DBR, 1964:47 \& 448).

Bung Karno memperkuat argumennya dengan menampilkan contoh tokoh-tokoh dunia yang ia anggap cara kerjanya hebat, misalnya Luther, Marx, Trotzky, Mussolini, Hitler hingga Nabi Muhammad. Bahasa dan gaya berbahasa Bung Karno tentang tokoh tersebut: "Mereka punja pikiran mereka bantingkan ditengah-tengah chalajak sehingga mendengung dan mengilat!" "Sejak hari pertama Nabi Muhammad buka suara terang-terangan dikota Mekkah, ia sudah bikin “onar,” ...(DBR, 1964:447-448). 
Dalam teks yang berjudul, "Sekali lagi: Bukan "Djangan Banjak Bitjara, Bekerdjalah”, tetapi “Banjak Bitjara, Banjak Bekerdja”, Bung Karno menanggapi tuduhan bahwa dirinya nasionalis destruktif, tukang gembar-gembor yang tidak mendirikan apa-apa dengan rupa, bangun dan perangai bahasa seperti:

"... bahwa bekerdja itu tidak hanja berarti mendirikan barang-barang .... ... bahwa perkataan mendirikan itu juga boleh dipakai untuk barang jang abstrak, jakni juga bisa berarti mendirikan semangat, mendirikan keinsjafan, mendirikan harapan, mendirikan ideologi atau gedung kedjiwaan atau artileri kedjiwaan jang menurut sedjarah dunia achirnja adalali artileri jang satu-satunja jang bisa menggugurkan sesuatu stelsel” (DBR, 1964:216).

Bung Karno dalam pidato pembelaannya yang berjudul Indonesia Menggugat di muka hakim kolonial di Bandung tahun 1930 dengan tuduhan delik penyebaran rasa benci lewat propaganda politiknya PNI untuk menggulingkan kekuasaan Hindia Belanda menampilkan rupa dan perangai bahasa serta strategi atau gaya berbahasa seperti:

”O, memang Tuan-tuan hakim, kami punja bahasa adalalah bahasa jang radikal. Kami punja bahasa bukanlah bahasa nenek-nenek jang sudah djatuh pingsan kalau mendengar kata "kemerdekaan", kami punja pidato bukanlah pidato paderi atau pendeta di dalam geredja atau pidato djuru chotbah dalam mesdjid. Kami adalali nasionalis revolusioner, nasionalis jang radikal, nasionalis kepala banteng!" (Indonesia Menggugat, Pratiwi (ed.), 2001:244).

"O, memang kami sering mengatakan bahwa kami adalali kaum revolusioner, kami sering menjebut PNI itu suatu partai revolusioner! PNI memang sedjak awal adalah suatu partai revolusioner! Kalimat dalam surat dakwaan bahwa PNI kemudian mendjadi revolusioner, PNI adalah revolusioner sedjak hari lahirnja! Tetapi kata revolusioner dalam makna kami, sama sekali tidak berarti "mau membuat pemberontakan" atau mendjalankan suatu pelanggaran hukum". Kata revolusioner ... berarti radikal, mengadakan perubahan dengan lekas, omvormend in snel tempo. ... kebalikan kata sabar ... kata sedang. Kami kaum PNI bukan kaum sedang ... bukan kaum "uler kumbang" jang selamanja kami sebut "kapuk", ... .Kami adalah kaum Kepala Banteng." (Indonesia Menggugat, Pratiwi (ed.), 2001:150).

Bung Karno memperkuat pendefinisian revolusioner dengan menampilkan contoh tokoh sejarah, misalnya dengan rupa, perangai dan gaya bahasa seperti: "Prof. Ensten sudah merevolusikan segenap ilmu alam," "Jezus Kristus seorang revolusioner," (Indonesia Menggugat, Pratiwi (ed.), 2001:149150). Contoh lain bentuk, rupa dan perangai gaya bahasanya, seperti: 
"Amboi! Golok, bom dan dinamit! Kami dituduh golok-golokan, bom-boman, dinamit-dinamitan! Seperti tidak ada sendjata jang lebih tadjam lagi daripada golok, bom dan dinamit! Seperti tidak ada sendjata jang lebih kuasa lagi daripada puluhan kapal perang, ratusan kapal udara, ribuan, ketian, miljunan serdadu darat. Seperti tidak ada sendjata semangat lagi jang djikalau sudah sadar dan bangkit serta berkobar-kobar dalam kalbu rakjat, lebih hebat kekuasaannya dari seribu bedil dan seribu meriam, ja, seribu armada laut ...! Orang menuduh kami mau membuat rame-rame dengan mertjon sumet dan mertjon banting! Seperti tidak ada ilmu ke-Timuran lagi ...." (dilanjutkan dengan menyebutkan syair dalam buku Bagawat Gita; Indonesia Menggugat, Pratiwi, 2001:153-154).

"O, memang, kami memang pernah mengatakan "rubuhkanlah imperialisme!" rubuhkanlah kapitalisme! .... Imperialisme djahat, kapitalisme angkara murka .... Tuan-tuan hakim seperti jang kami uraikan pada awal pidato kami dengan didukung dalil-dalil orang-orang ternama, bukanlah Bangsa Belanda, bukanlah bangsa asing jang lain, bukanlah kaum B.B., Bukanlah kekuasaan pemerintah, bukanlah suatu badan atau materialisme-kapitalisme dan imperialisme seperti tiap-tiap perkataan jang berachiran "isme" adalah suatu faham, suatu pengertian, suatu sistem! Sistem ini yang merusak, jang mencelakakan, jang djahat, jang harus dirubuhkan, bukan pemerintah! Amboi, adakah kami begitu goblok, adakah kami kering otak atau barangkali miring otak mengira bahwa imperialisme $=$ kekuasaan pemerintah, kapitalisme $=$ bangsa asing" (Indonesia Menggugat, Pratiwi, 2001:240).

\section{Fenomena Kebahasaan}

Bung Karno sebagai salah satu motor pergerakan kebangsaan. Motor penggeraknya cenderung terdapat pada perilaku bahasanya. Ada fenomenafenomena perilaku kebahasaannya yang menarik untuk dikaji secara serius atau ilmiah. Dua di antaranya adalah, (1) fenomena gerakan penggunaan bahasa pembebasan atau demokratis, (2) fenomena bilingualisme dan pengaruhnya terhadap tumbuh-kcmbangnya benih-benih kesadaran baru dalam melihat dan menyelesaikan permasalahan bangsanya.

Fenomena yang pertama. Bung Karno dalam mengekspresikan kognisi dan afeksinya ke dalam bahasa cenderung kurang mempertimbangkan ketentuanketentuan normatif sosial-budaya Jawa yang menjadi konvensi berkomunikasi. Dalam rapat pleno tahunan yang diselenggarakan oleh Jong Java cabang Surabaya tahun 1921 Bung Karno memulai ceramahnya dengan menggunakan bahasa Djawa Dipa (ngoko) sehingga ketua rapat menghentikannya dan rapat berakhir kacau. Sebulan kemudian ia juga mengusulkan agar surat kabar Jong 
Java diterbitkan dalam bahasa Melayu. Sejak peristiwa tersebut Bung Karno mendapat julukan Bima, tokoh pewayangan pemberani, tidak bisa berbahasa halus dan memang merupakan pahlawannya di masa kecilnya (Dahm, dalam Basari, 1987). Bernhard Dahm menyebutnya "Sekolah Sarekat Islam;" artinya, Bung Karno selama waktu tertentu belajar kepada Sarekat Islam (SI). Sedangkan SI menganggap hubungan sosial Jawa yang hierarkis, seperti kaula-gusti, ngokokromo sebagai "simbol penindasan yang paling kentara " (Dahm, dalam Basari, 1987).

Kecenderungan Bung Karno untuk menggunakan bahasa ngoko dan gaya bahasa seperti tokoh pewayangan Bima mengisyaratkan adanya ruang pemahaman dan kesadaran baru dalam dirinya. Pemahaman dan kesadaran baru tersebut dapat dipahami sebagai akibat. Berarti, ada sebab atau motif dan tujuan tertentu. Sekilas, penyebabnya imitasi dan identifikasi terhadap Bima atau SI dalam konteks tujuan untuk mencari jalan keluar dari pola hierarki hubungan sosial Jawaisme. Akan tetapi. Bung Karno sebagai elit politik dan intelektual tampaknya terlalu menyederhanakan jika dipahami dari perspektif behaviorisme. Fenomena gerakan penggunaan ragam bahasa yang bernuansa pembebasan atau demokratis (ngoko) oleh seorang tokoh pergerakan Bung Karno merupakan indikasi bahwa ada faham kebenaran baru yang mengusik dan menguasai Bung Karno. Faham kebenaran baru yang tercermin dalam bahasa dan cara membahasakannya. Bahasa yang mewakili arus pemikiran baru. Bahasa yang mewakili pandangan dunia baru. Jika arus pemikiran baru tersebut bernuansa politik maka bahasa politiknya berindikasi memiliki spektrum, corak, rupa atau perangai tertentu dalam mengartikulasikan politik. Pengartikulasian politik dengan bahasa dan gaya yang dapat berimplikasi politik dan sosial, misalnya akulturasi, asimilasi dan transformasi kesadaran dan partisipasi politik yang lebih mengikat kebersamaan dalam usaha memecahkan masalah kepentingan masa depan bersama sebagai bangsa yang berdaulat.

Apakah fenomena penggunaan bahasa ngoko tersebut termasuk apa yang oleh Benedict R. Anderson dikategorikan sebagai "petualangan bahasa baru, 
dengan perangainya yang heroik-politis, kata-katanya hidup dan bergetar, terdapat kontras mencolok dengan bahasa Jawa, yang kata-kata emosionalnya mengalun dan merdu ...? “ (Santosa, 2000:298-289). Meskipun tesis Anderson tersebut mengarah pada watak bahasa Melayu rendah atau bahasa Indonesia, tetapi fenomena penggunaan bahasa ngoko oleh Bung Karno semakin membuka peluang bagi masyarakat majemuk terjajah untuk lepas dari sekat-sekat psikologis elitisme dan feodalisme berbahasa. Penggunaan ragam ngoko menjadi wacana publik dan dapat berefek pembebasan sekat-sekat sosial dan politik sehingga masyarakat majemuk terjajah semakin bebas-lugas berpartisipasi mengartikulasikan dan mengekspresikan kesadarannya, baik kesadaran politik, sosial maupun ekonominya. Fenomena kebahasaan tersebut oleh Bernhard Dham dipahami, "konsep Jawa semakin didesak oleh konsep Indonesia" (Dahm. dalam Basari, 1987:43). Dengan maksud serupa, Hilmar Farid memahaminya dengan menyatakatan, "tindakan menggunakan bahasa Jawa ngoko memperluas kesempatan bagi rakyat untuk membentuk konsep bangsa” (Latif dan Ibrahim (ed.), 1996:19).

Apapun perspektif pemahaman tentang penggunaan ragam ngoko, pembentukan bangsa yang bertanah air Indonesia tidak terpisah dengan fenomena pilihan bahasa dan gaya berbahasa. Konsep bangsa dan Indonesia, baik dalam perspektif bioiogis-geografis maupun perspektif politis, bergerak menuju satu rumah bahasa Nasional melalui wacana ngoko, wacana politik, sosialisme, perburuhan, kerakyatan, Marhanisme, agama versus Kapitalisme, Liberalisme dan Imperialisme-Kolonialisme. Sumpah Pemuda, 28 Oktober 1928 merupakan periode penegasan perkawinan bangsa, bahasa dan tanah air dalam satu rumah "Indonesia." Ketiganya bergerak menuju satu rumah Indonesia melalui praktikpraktik wacana atau retorika dengan bahasa dan gaya penuturan yang dapat merepresentasikan kepentingan bersama masyarakat majemuk terjajah.

Fanomena kedua, bilingualisrne. Bagaimana bahasa Indonesia dapat menjadi rumah dan katalisator atau transmisi mengelola keragaman pemikiran atau pemahaman menuju kesadaran bersama versus Kapitalisme-lmpenalisme 
sehingga terbentuk imaji satu bangsa, satu bahasa dan satu tanah air Indonesia yang beku dan baku? Jawabannya dapat beragam, satu di antaranya adalah bilingualisme. Bung Karno salah satu motor gerakan kebangsaan yang bilingual.

Ia lahir dari lingkungan keluarga yang berbahasa budaya Jawa dan tumbuh menjadi cendekiawan dari sekolahan Eropa-Belanda selama kurang lebih dua puluh tahun. Bung Karno diperkaya wawasannya melalui sekolah Eropa dan bahasa Eropa-Belanda. Bung Karno bisa dan biasa menggunakan dua bahasa atau lebih: bahasa Jawa, bahasa Indonesia dan bahasa asing, seperti bahasa Belanda dan bahasa Inggris.

Bilingualisme dapat dipahami sebagai fenomena kebahasaan dan kebudayaan. Bahasa dan kebudayaan tidak terpisah meskipun keduanya berbeda. Bahasa bagian dari kebudayaan, bahasa sumber kebudayaan. Mempelajari, menciptakan dan mengembangkan budaya dapat melalui bahasa. Jika kebudayaan dipahami sebagai kontrak sosial maka ia merupakan sistem komunikasi. Artinya, kebudayaan adalah sistem tanda yang menyediakan aturan, tatabahasa sebagai pedoman berperilaku kolektif, pedoman tatacara berbahasa. Dengan dasar pemahaman tersebut maka dapat ditarik asumsi bahwa perbedaan bahasa dapat mencerminkan perbedaan budaya. Sebaliknya, perbedaan budaya dapat mencerminkan perbedaan bahasa. Oleh karena itu, jika Bung Karno seorang bilingual, bisa dan biasa menggunakan bahasa Jawa, bahasa Indonesia dan bahasa asing, seperti bahasa Belanda atau bahasa Inggris maka dalam dirinya (kamus mental) telah terjadi kontak dua bahasa, sekaligus kontak dua budaya; terjadi alih kode, sekaligus alih budaya; telah terjadi campur kode, sekaligus campur budaya; telah terjadi interferensi bahasa, sekaligus interferensi budaya; telah terjadi integrasi bahasa, sekaligus integrasi budaya. Kesimpulannya, bilingualisme memperlancar proses akulturasi dan asimilasi budaya dan bahasa.

Bilingualisrne memungkinkan Bung Karno mengenal dan mengendapkan dalam memorinya konsep-konsep Sosialisme, Komunisme, Marxisme, Agamaisme, perburuhan, kerakyatan, Kapitalisme, Imperialisme-Kolonialisme. Dengan bilingualisrne, perbendaharaan bahasa dan budaya diperkaya dan 
diperluas. Dengan bilingualisme, suatu bahasa dapat diperkaya atau memperkaya bahasa yang lain; suatu bahasa dapat dipengaruhi atau mempengaruhi bahasa yang lain. Hipotesis Relativitas Kebahasaan dari Sapir-Whorf menjelaskan tentang pengaruh bahasa pada pikiran: "setiap bahasa memaksa atau memberikan suatu pandangan dunia bagi penuturnya;" "bentuk dan struktur bahasa seseorang mengatur cara berpikir dan tindak laku orang" (Nababan, 1992:140-161 dan 1984:52).

Berdasar pada hipotesis Relativitas Kebahasaan Sapir-Whorf maka bahasa asing-Belanda dalam diri Bung Karno dapat menjadi jembatan perantara atau pembuka jalan bagi perubahan modalitas kesadaran dan terbentuknya struktur serta konsep pemikiran kritis-radikal versus pemerintahan kapitaliskolonial Belanda. Dengan kata lain, kemampuan dan kebiasaan menggunakan bahasa Belanda oleh para cendekiawan idealis (bilingualisme) dapat berdampak (1) terserap ke dalam dirinya konsep-konsep dan struktur pemikiran yang dapat membangun dan membentuk modalitas kesadaran baru sebagai benih dan cikalbakal munculnya elit intelektual revolusioner; (2) mempercepat tumbuhkembangnya bahasa Indonesia sebagai bahasa Nasional karena jika hanya dengan bahasa asing-Belanda efektifitas komunikasi horisontal dengan rakyat majemuk terjajah tidak efektif. Bukan saja karena pertimbangan tidak komunikatif, tetapi bahasa asing-Belanda di mata mereka dinilai bernuansa bahasa krama, elitis dan feodalis. Dengan bahasa Indonesia yang lahir dari ibu bahasa Melayu pasar dengan perangainya yang lingua franca, bahasa inter-etnis atau ras, tanpa nuansa status menjadi solusi positif untuk membangun komunikasi politik horisontal. Indonesia sebagai kesatuan politik dan geografis semakin diperjelas bentuknya oleh bahasa yang diperkaya dan dipermodern oleh bahasa Belanda para cendekiawan nasionalis-idealis; (3) bilingualisme memperlancar dan mempercepat lahirnya bahasa, bangsa dan tanah air Indonesia. Dengan maksud sama, Benedict R.O.G. Anderson mengatakan:

"Semata karena kekuasaan Belanda terbentang lebih luas dibandingkan kelompok suku mana pun, dan cengkeramannya sudah sedalam stratifikasipenuh masyarakat tradisional, sehingga Belanda hanya bisa ditanggapi berdasarkan istilah-istilah yang telah dibentuknya sendiri. Wahana untuk 
memahami, dengan demikian, haruslah bahasa Belanda; dan kemudian wahana untuk menyerang berikutnya adalah bahasa Indonesia (bahasa Melayu revolusioner). Cukup paradoksal memang, bahwa perkembangan bahasa Indonesia sebagai bahasa nasional hanya dimungkinkan manakala bahasa Belanda telah menjadi bahasa dalam diri para intelegensia. Hanya dengan begitu bahasa Indonesia bisa berkembang untuk menyerap pemikiran baru, dan kemudian menyebarluaskannya ke masyarakat kolonial" (Santosa, 2000:292).

\section{Kesimpulan}

Bung Karno membahasakan dan mengkomunikasikan buah pikirannya kepada publik tidak steril dari motif dan tujuan. Penggunaan bahasanya sebagai fungsi, seni, strategi atau gaya untuk mencapai tujuan. Penggunaan bahasanya merupakan fenomena sosiopragmatik. Penggunaan bahasanya bercorak fungsional daripada formal. Dengan dasar tersebut maka teks yang terhimpun dalam DBR berkategori sebagai rekaman praktik retorika persuasif, praktik wacana dan tindak bahasa dalam situasi komunikasi zaman pergerakan kebangsaan menuju Indonesia merdeka, lepas dari penjajahan.

\section{Referensi}

Alfian. 1986 Tranformasi Sosial Budaya dalam Pembangunan. Jakarta: UI Press.

Aminuddin. 1995. Stilistika Pengantar Memahami Bahasa dalam Karya Sastra. Semarang: IKIP Semarang Press.

Anderson, Benediet, R.O.G. 1990. a Language and Power Eksploring Political Cultures in Indonesia (Kuasa-Kata Jelajah Budaya-budaya Politik di Indonesia). 2000. Penerjemah Revianto Budi Santoso. Yogyakarta: Mata Bangsa.

1983. b. Imagined Communities (Komunitas-Komunitas Terbayang). 2002. Penerjemah Omi Intan Naomi: Yogyakarta: INSIST Press.

Berman, Laine. 2001. "Kepribadian dalam Tuturan Bahasa Jawa.” Makalah Disajikan di Kongres Bahasa Jawa III, Juli, 11-12 2001.

Budiman, Maimake. 1999. "Jatidiri Budaya dalam Proses "National-Building" di Indonesia: Mengubah Kendala Menjadi Aset." Wacana Jurnal Ilmu Pengetahuan Budaya. Vol. I, No. 1, hal. 20-23.

Brown, Gillian and Yule, George. 1996. Analisis Wacana. Penerjemah I. Soetikno P. Jakarta: Gramedia Pustaka Utama. 
Dahm, Benhard. 1969. Sukarno and the Struggle for Indonesian Independence (Sukarno dan Perjuangan Kemerdekaan Indonesia). 1987. Penerjemah Hasan Basari. Yogyakarta: LP3ES.

Evan, James R. 1991. Creative Thinking in the Decision and Management Sciences (Berpikir Kreatif pada Ilmu Pengambilan Keputusan dan Manajemen). 1994. Penerjemah Bosco Carvallo. Jakarta: Bumi Aksara.

Effendy, Onong Uchjana. 1993. Dinamika Komunikasi. Bandung: Remaja Rosdakarya.

Eriyanto. 2001. Analisis Wacana Pengantar Analisis Teks Media. Yogyakarta: LkiS.

Fisher, B. Aubrey. 1978. Perspectives on Human Communication (Teori-Teori Komunikasi). 1986. Penerjemah Soejono Trimo. Bandung: Remaja Rosdakarya.

Faucault, Michel. 1972. The Archeologi of Knowledge (Arkeologi Pengetahuan). 2002. Penerjemah H.M. Mochtar Zoenii. Yogyakarta: Qalam.

Geertz, Glifford. 1974. The Interpretation of Cultures: Selected Essays (Kebudayaan dan Agama). 1992. Penerjemah Francisco Budi Hardiman. Yogyakarta: Kanisius.

Gidden, Antony. 1984. The Constitution of Society: the Outline of the Theory of Structuritation (Teori Strukturasi untuk Analisis Sosial). Maret 2003. Penerjemah Adi Loka Sujono. Pasuruan: Pedati.

Goleman, Daniel. 1995. Emotional Intelligence (Kecerdasan Emosional Mengapa EI Lebih Penting daripada IQ). 2003. Penerjemah T. Hermaya.Jakarta: Gramedia Pustaka Utama.

Halliday, M.A.K. and Ruqaya Hasan. 1985. Language, Context and Text: Aspects of Language in a Social-Semiotic Perspective (Bahasa, Konteks dan Teks: Aspek-Aspek Bahasa dalam Pandangan Semiotik Sosial). 1992. Penerjemah Asrudin Barori Tou. Yogyakarta: Gadjali Mada University Press.

Hidayat, Komaruddin. 1996. Memahami Bahasa Agama Sebuah Kajian Hermeneutik. Jakarta: Paramadina.

Hikam, Muhammad A.S., 1996. "Bahasa dan Politik: Penghampiran DiscuisivePractice." Yudi Latif dan Idi Subandy Ibrahim (ed). Bahasa dan Kekuasaan Politik Wacana di Panggung Orde Baru. Bandung: Mizan.

Djajasudarma, T.Fatimah. 1994. Wacana Pemahaman dan Hubungan Antarunsur. Bandung: PT. Eresco.

Joko Suyono, Seno. 2002. Tubuh yang Rasis Telaah Kritis Michel Foucault atas Dasar-Dasar Pembentukan Diri Kelas Menengah Eropa. Yogyakarta: Pustaka Pelajar. 
Kartodirdjo, Sartono, Marwati Djoened Poeponegoro, Nugroho Notosusanto.1977. Sejarah Nasional Indonesia IV. Departemen Pendidikan dan Kebudayaan. Jakarta: Balai Pustaka.

Kartomihardjo, Soeseno. 1993. “Analisis Wacana dengan Penerapannya pada Beberapa Wacana." Bambang Kaswanti Purwo (Penyunting). PELLBA 6. Yogyakarta: Kanisius.

Keraf, Gorys. 1992. a. Argumentasi dan Narasi. Jakarta: Gramedia Pustaka Utama.

--------. 2000. b. Diksi dan Gaya Bahasa. Jakarta: Gramedia Pustaka Utama.

Kuhn, Thomas S. 1970. The Structure of Scientific Revolutions (Peran Paradigma dalam Revolusi Sains). 2000. Penerjemah Tjun Surjaman. Bandung: Remaja Rosdakarya.

Lauer, Robert H. Perspeetives on Social Change (Perspektif tentang Perubahan Sosial). 1993. Penerjemah Alimandan. Jakarta: P.T. Rineke Cipta.

Leech, Geofirey. The Principles of Pragmatics (Prinsip-Prinsip Pragmatik). 1993. Penerjemah MD. Oka. Jakarta: UI Press.

Malik, Dedy Djamaluddin dan Yosal Irianto. 1994. Komunikasi Persuasif. Bandung: Remaja Rosdakarya.

Mapes, James J. 2003. Quantum Leap Thinking: An Owner's Guide to the Mind (Quantum Leap Thinking: Pedoman Lengkap Cara Berpikir). 2003. Penerjemah Basuki Heri Winarno. Surabaya: Ikon Teralitera.

Mintz, Jeanne S. Mohammed, Marx and Marhaen: The Roots of Indonesian Socialism (Muhammad, Marx dan Marhaen: Akar Sosialisme Indonesia). 2002. Penerjemah Zulhilmiyasri. Yogyakarta: Pustaka Pelajar.

Mulder, Niels. Mysticism in Java Ideology in Indonesia (Mistisisme Jawa Ideologi di Indonesia). 2001. Penerjemah Noor Cholis. Yogyakarta: LkiS.

Nababan, Sri Utari Subyakto. 1992. Psikolinguistik: Suatu Pengantar. Jakarta. Gramedia.

Nimmo, Dan. Political Communication and Publik Opinion in America (Komunikasi Politik: Komunikator, Pesan dan Media). 1993 Penerjemah Tjun Surjaman. Bandung: Remaja Rosdakarya.

Noorsena, Bambang. 2001. Religi dan Religiusitas Bung Karno Keberagamaan Mengokohkan Keindonesiaan. Denpasar Bali: Jagadhita.

Oetomo, Dede. 1993. "Pelahiran dan Perkembangan Analisis Wacana." Bambang Kaswanti Purwo (Penyunting). PELLBA 6. Yogyakarta: Kanisius.

Purwo, Bambang Kaswanti. 1989. Pragmatik dan Pengajaran Bahasa Menyibak Kurikulum 1984. Yogyakarta: Kanisius.

Purwasito, Andrik. 2002. Imajeri India Studi Tanda Wacana, Surakarta: Pustaka Cakra. 
Rakhmat, Jalaluddin. 1995. a. Metode Penelitian Komunikasi. Bandung: Remaja Rosdakarya.

.1996. b. "Komunikasi dan Perubahan Politik di Indonesia." Yudi Latif dan Idi Subandy Ibrahim (ed). Bahasa dan Kekuasaan: Politik Wacana di Panggung Orde Baru. Bandung. Mizan.

--------.2001 c. Psikologi Komunikasi. Bandung: Remaja Rosdakarya.

--------.1992. d. Retorika Modern Pendekatan Praktis. Bandung: PT. Rosdakarya.

Rasuanto, Bm. 1998. "Diperlukan Reformasi Kebudayaan.” Imam WaJujo dan Kons Kleden (ed). Dialog Indonesia Kini dan Esok. Jakarta: Leppenas.

Ricoeur, Paul. The Interpretanon Theory: Discourse and the Surplus of Meaning (Filsafat Wacana Membelah Makna dalam Anatomi Bahasa). 2002. Penerjemah Musnur Hery. Yogyakarta: IRCiSoD.

Sutjaja, I. Gusti Made. 1990. "Perkembangan Teori M.A.K. Halliday.” Bambang Kaswanti Purwo (Penyunting). PELLBA 3. Yogyakarta. Kanisius.

Sudibyo, Agus. 1990. Citra Bung Karno. Analisis Berita Pers Orde Baru. Yogyakarta: BIGRAF Publishing.

Sugiharto, I. Bambang. 1996. Postmodernisme Tantangan Bagi Filsafat. Yogyakarta: Kanisius.

Sudjiman, Panuti. 1993. Bunga Rampai Stilistika. Jakarta: PT. Pustaka Utama Grafiti.

Sukarno. a. Dibawah Bendera Revolusi. Jilid Pertama. Cetakan Ketiga. Tahun 1964. Panitia Penerbit H.Mualliff Nasution.

Sukarno. b. 2001. Indonesia Menggugat. Endah Duri Pratiwi (Editor Bahasa). Yogyakarta: Yayasan untuk Indonesia.

Spradley, James P. The Etnographic Interview (Metode Etnografi). 1997. Penerjemah Misbah Zulfa Elizabetii. Yogyakarta: Tiara Wacana.

Zoest, Aart van. 1980. Waargebeurd en toch gelogen (fiksi dan nonfiksi dalam kajian semiotik). 1991. Penerjemah Manoekmi Sardjoe. Jakarta: Intermasa. 